\section{A rete in the right whale}

SIR - Whales maintain a homeothermic body temperature by losing heat to the surrounding water. The skin of the flippers, dorsal fin and tail flukes are the most effective areas used for heat dumping. The rest of the body is well insulated by subdermal blubber. Right whales (Eubalaena glacialis) have more of a problem maintaining a normal body temperature than other whales because they have a low surface area-to-volume ratio, extremely thick blubber, and no dorsal fin ${ }^{1}$. The New England Aquarium, Boston, acquired a neonate right whale after it died (it had been found at Cumberland Island, Georgia, in January 1990). Dissection of the whale revealed a previously undescribed organ, an intraoral rete, that aids heat loss.

A rete, a body of convoluted blood vessels commonly found in mammals to store blood and regulate blood flow ${ }^{2}$, connects arteries to veins, arteries to arteries and veins to veins ${ }^{3}$. Retial bodies were described first by Galen ${ }^{4}$. The intraoral rete of the right whale runs the full internal length of the upper jaw, with a total length of $83.8 \mathrm{~cm}$ in an animal $4.12 \mathrm{~m}$ long. It is an elongated ' $\mathrm{Y}$ ' in shape, terminating in two large lobes. These lobes occupy a large gap in the baleen filter array.

Gross sections revealed a twisted mass of blood vessels, some muscle and no blubber. The rete is associated with a notch in the pterygoid plate of the skull. It connects with the basicranial rete, observed by Ommaney ${ }^{5}$ at the base of the skull external to the foramen magnum, allowing control of temperature for blood entering the brain. The brain would be protected from hyperthermic blood flow, an important mechanism because the brain is easily damaged by high temperatures.

Microscopy revealed a complex structure. The surface was covered with stratified squamous epithelium. Smooth muscle was present in three orientations from the maxilla: longitudinal groups appeared to run the length of the organ at the lateral extremity, and three to five bands of smooth muscle crossed the width of the rete in the horizontal plane. Small muscles radiated vertically from the jaw, extending from the longitudinal groups to the dermis. Very little areolar tissue was found.

Veins dominated the vascular structures. The lining of many veins resembled the transitional epithelium of a bladder. Cells were piled on each other in collapsed vessels that were clearly capable of much larger volumes. Arteries were clearly under-represented.

Small arterioles were found only in association with nerve bundles. Lymphatic vessels were seen scattered throughout the organ, but no lymphoid nodules were found.

A striking feature of the rete is a massive innervation. This is probably from the second division of the trigeminal nerve which serves the upper jaw in all mammals, and may be for vascular control or for temperature sensing. There was an abundant distribution of encapsulated mechanoreceptors at the dermis-epidermis boundary, possibly for temperature or hydrodynamic flow sensing.

The histological composition and anatomical position of the rete strongly suggest a thermoregulatory function. The organ functions by flushing its surface with cold water when the mouth is open, accomplished by relaxing the internal musculature and allowing the venous retial structure to flood with hyperthermic blood. As cold water flows over the uninsulated gingival surface, heat is readily lost.

\title{
Childhood thyroid cancer in Belarus
}

SIR - There is little doubt that the number of children reported to have thyroid cancer increased dramatically in radiation-contaminated areas of the Ukraine in 1990 (ref. 1) and in Belarus in 1990-91 (ref. 2).

It must be borne in mind, however, that intensive surveillance for thyroid cancer began in these areas in 1990 and that many of the cancers might perhaps never have been diagnosed otherwise. Histological examination of the thyroid from asymptomatic subjects is known to result in the detection of 'occult' papillary carcinomas which are indolent clinically and would probably never progress to cause frank symptomatic disease. At autopsy, the prevalence of occult papillary carcinoma is $2 \%$ at age $0-15$ and $22 \%$ at age 16-30 (ref. 3). Most occult lesions found at autopsy with a diameter greater than $2 \mathrm{~mm}$ show invasion into the surrounding tissue ${ }^{4}$. Fewer than half the thyroid cancers which cause clinical disease are papillary ${ }^{5}$ and the fact that 128 out of 131 reported in Belarussian children were papillary carcinomas suggests that many, including those described as invasive, might be occult.

More information is needed on the way the thyroid cancers manifested themselves in children from Belarus, on the frequency of thyroid biopsies over time and in different regions, and on the geographical variation in reported thyroid cancer incidence. In particular, the following issues need to be addressed.

First, how many thyroid cancers in children manifested themselves with clin-
Whales do not have sweat glands in the skin. The intraoral rete is an adaptive organ in balaenid whales that allows them to control their internal temperature by losing heat to oceanic water in various circumstances. We suggest that the intraoral rete may be present within and restricted to the Balaenidae (right, bowhead and pygmy right whales).

\section{T. J. Ford Jr}

Department of Biology,

Boston College,

Chestnut Hill,

Massachusetts 02167, USA

S. D. Kraus

New England Aquarium.

Boston,

Massachusetts 02110, USA

1. Omura, H. et al. Sci. Rep. Whales Res. Inst. 21 (Tokyo, 1969)

. Ask-Upmark, E. Acta Psychiat. Neurol. Suppl. VI (1935)

3. Slijper, E. J. Whates (Cornell University Press. 1962)

4. Galen. De Usu Partius Corpore Humanis Libris (ed. Kuhn. P) IX cap IV Medicor Craecor Opera (Olms. Hildesheim. 1965).

5. Ommaney. F. D. The Vascular Networks (Retia Mirabilia) of the Fin Whale (Balaenoptera Physalus) (Discovery Reports, London, 1932)

ical disease? How many cancers were picked up through investigation of asymptomatic thyroid enlargement? Has the number of thyroid biopsies in children increased over time and does this vary by region? Has the proportion of biopsies in which cancer was diagnosed changed over time and does it vary by region?

Second, what are the incidence rates of childhood thyroid cancer in each region? (It is unsatisfactory to report number of cases without referring to population size.) How do these relate to the overall pattern of radiation contamination in Belarus? If due to radiation, thyroid cancer incidence rates should be highest in the most contaminated districts (raions) of Gomel, that is, those which are very close to the Ukrainian border. Data on thyroid cancer incidence rates in each raion within Gomel are readily accessible and need to be reported.

Finally, an epidemic of thyroid cancer due to radiation exposure would be expected to continue over many years. It will be important to monitor trends in the future. The apparent increase in childhood thyroid cancer in the Ukraine and Belarus is of obvious concern, but it

\footnotetext{
1. Prisyazhiuk, A., Pjatak, O. A., Buzanov, V. A. Reeves, G. K. \& Beral, V. Lancet 338. 1334-1335 (1991) Kazakov V S. Demidchlk. E. P. \& Astakhova L N. Nature 359. 21-22 (1992)

3. Franssila, K: O. \& Harach, H. R. Cancer 58, 715-719 (1986).

4. Harach, H. R., Franssila, K. 0. \& Wasenius, V.-M. Cance 56, 531-538 (1985)

5. Pettersson, B., Adami, H.-O., Wilander. E. \& Coleman M. P. Int. J. Cancer 48. 28-33 (1991)
} 